\title{
Adult Attachment Security and Symptoms of Depression: The Mediating Roles of Dysfunctional Attitudes and Low Self-Esteem
}

\author{
John E. Roberts and Ian H. Gotlib \\ Northwestern University
}

\author{
Jon D. Kassel \\ University of Pittsburgh
}

\begin{abstract}
Three studies investigated the relation between adult attachment security and symptoms of depression. Study 1 examined the overall magnitude of the association between adult attachment and depression, and Studies 2 and 3 tested whether this relation was mediated by dysfunctional attitudes and low self-esteem. Results from the three studies were consistent with a mediation model. This model suggests that insecure aduit attachment styles are associated with dysfunctional attitudes, which in turn predispose to lower levels of self-esteem. Such depletions in self-esteem are directly associated with increases in depressive symptoms over time. Insecure attachment appears to lead to depressive symptoms in adulthood through its impact on self-worth contingencies and self-esteem.
\end{abstract}

It has become increasingly clear that depression involves both interpersonal and cognitive dysfunctions that are hypothesized to play a crucial role in the etiology and maintenance of the disorder (e.g., Barnett \& Gotlib, 1988; Gotlib, 1992; Joiner \& Metalsky, 1993; Teasdale \& Barnard, 1993). With respect to interpersonal difficulties, depression has been linked to interpersonal rejection (Gotlib \& Robinson, 1982), inadequate social support in times of crisis (Brown, Bifulco, Harris, \& Bridge, 1986), and marital conflict (Beach, Sandeen, \& O'Leary, 1990). Furthermore, relapse in depression is associated with family criticism (Hooley, Orley, \& Teasdale, 1986; Hooley \& Teasdale, 1989; Vaughn \& Leff, 1976), whereas speed and likelihood of recovery is predicted by low levels of family conflict and positive overall family functioning (Corney, 1987; Keitner, Miller, Epstein, Bishop, \& Fruzzetti, 1987; Rounsaville, Weissman, Prusoff, \& Herceg-Baron, 1979; Swindle, Cronkite, \& Moos, 1989). In terms of cognitive dysfunctions, depression is marked by a variety of negative thought patterns, including dysfunctional attitudes (see Barnett \& Gotlib, 1988; Haaga, Dyck, \& Ernst, 1991, for reviews). Importantly, such negative thinking is associated with relapse of depression (Simons, Murphy, Levine, \& Wetzel, 1986), and its absence predicts recovery from this disorder (Brown, Bifulco, \& Andrews, 1990; Dent \& Teasdale, 1988; Lewinsohn, Steinmetz, Larson, \& Franklin, 1981; Steinmetz, Lewinsohn, \& Antonuccio, 1983; Williams, Healy, Teasdale, White, \& Paykel, 1990).

John E. Roberts and Ian H. Gotlib, Department of Psychology, Northwestern University; Jon D. Kassel, Department of Psychology, University of Pittsburgh.

Correspondence concerning this article should be addressed to John E. Roberts, who is now at Department of Psychology, State University of New York, Park Hall, Box 604110, Buffalo, New York 14260-4110.
Recently, investigators have begun to develop models that attempt to integrate cognitive and interpersonal processes in understanding vulnerability to depression (e.g., Blatt \& Homann, 1992; Carnelley, Pietromonaco, \& Jaffe, 1994; Gotlib \& Hammen, 1992; Joiner \& Metalsky, 1993; Lewinsohn, Hoberman, Teri, \& Hautzinger, 1985; Safran \& Segal, 1990; Swallow \& Kuiper, 1988) . Importantly, several of these approaches place a critical emphasis on attachment relationships in understanding the developmental trajectory of vulnerability, as well as in understanding the way in which interpersonal patterns become internalized as cognitive vulnerabilities ( see Whisman \& McGarvey, in press). The current article reports three studies that begin the process of examining how adult attachment styles and cognitive factors might be related to symptoms of depression. In particular, we were interested in assessing whether the relation between attachment insecurity and depressive symptomatology is mediated by dysfunctional attitudes and low self-esteem. As we discuss below, whereas dysfunctional attitudes are conceptualized as reflecting maladaptive contingencies of self-worth (Kuiper \& Olinger, 1986), low self-esteem theoretically reflects the activation of such underlying cognitive vulnerabilities (Roberts \& Monroe, 1994; Segal \& Muran, 1993).

\section{Attachment Across the Life Span}

Bowlby $(1969,1973)$ posited that attachment behaviors result from an evolutionary biobehavioral system. This system provides a survival advantage by keeping young children close to care providers in times of threat and danger. Its internal, psychological set point is thought to be the child's felt security. Deviations from felt security activate the child's attachment behaviors, ideally leading to reestablishment of close contact with the caregiver who provides protection. Proximity to, and responsiveness from, the caregiver reestablish the child's experi- 
ence of felt security (Bretherton, 1985). Well-functioning attachment relationships allow young children to progressively explore their environments, knowing that they have a secure base to which to return in times of threat (Ainsworth, Blehar, Waters, \& Wall, 1978).

Given its evolutionary importance, it is widely believed that nearly all infants negotiate some form of attachment relationship (Bowlby, 1980; Hazan \& Shaver, 1994). However, individual differences in the behavior of central caregivers are thought to give rise to different forms of attachment. Three major variants of attachment have been delineated in the child literature. Securely attached children readily seek contact and comfort from their caregiver when reunited after brief separations. In contrast, anxious-ambivalent children react to caretaker reunions with vacillating expressions of proximity seeking and anger. They are not easily comforted and have difficulty exploring their environments even when the caretaker is nearby. Finally, children classified as anxious-avoidant respond to reunions with detachment; these children fail to seek comfort and security from their caregivers (Ainsworth et al., 1978).

In a seminal paper, Hazan and Shaver (1987) reported a study in which Ainsworth et al.'s (1978) three attachment categories were translated into brief descriptions of adult equivalents. Participants endorsed the description that they believed fit them best. Unfortunately, such typologies fail to acknowledge potential blendings among categories. For example, three individuals might endorse the secure prototype. However, whereas the first might feel that the anxious-ambivalent prototype was a very close second choice, the second individual might feel that the anxious-avoidant prototype was the next most descriptive. The third might feel that neither of the two anxious prototypes was self-descriptive in the least. Nevertheless, categorical approaches treat these three individuals as equivalent in terms of attachment style. In response to such issues, dimensional scales of adult attachment have been developed (e.g., Bartholomew \& Horowitz, 1991; Collins \& Read, 1990; Feeney, Noller, \& Hanrahan, 1994; West \& Sheldon-Keller, 1994). These instruments measure the extent to which participants fall on continuous measures of various dimensions of attachment-for example, how comfortable they are becoming close to attachment figures. Such dimensional ratings generally exhibit good psychometric properties, such as high internal consistency and good test-retest correlations over intervals of up to 2 months (Collins \& Read, 1990; Feeney et al., 1994; West \& Sheldon-Keller, 1994). Furthermore, dimensional ratings are more powerful statistically than are categorical ratings.

In terms of continuity across the life span, childhood attachment styles, at least with the primary caregiver, appear to be relatively stable between 12 and 18 months of age (Main \& Weston, 1981; Sroufe \& Waters, 1977; Waters, 1978), as well as between infancy and early childhood (Main, Kaplan, \& Cassidy, 1985). Although no research has tracked attachment styles longitudinally from early childhood to adulthood, cross-sectional studies have found proportions of adult attachment prototypes roughly equivalent to those found in infancy (e.g., Hazan \& Shaver, 1987; Mikulincer, Florian, \& Tolmatz, 1990; Mikulincer, Florian, \& Weller, 1993; Mikulincer \& Nachshon, 1991), a pattern of results consis- tent with the notion of continuity (Rothbard \& Shaver, 1994). In contrast to the continuity view, other investigators argue that extant measures of adult attachment, particularly self-report instruments, may be heavily influenced by current relationship functioning (Bartholomew, 1994; Kobak, 1994). Clearly, longitudinal research investigating the stability of adult attachment styles over time and across different relationships is critical. However, at present, the idea that most individuals maintain moderately stable attachment styles across the life span is tenable, particularly if their social environments remain relatively stable (Hazan \& Shaver, 1994).

\section{Attachment Security and Psychological Disturbance}

Despite the proliferation of studies examining the role of adult attachment styles in love relationships (e.g., Carnelley \& Janoff-Bulman, 1992; Collins \& Read, 1990; Feeney \& Noller, 1990; Hazan \& Shaver, 1987, 1990; Kobak \& Hazan, 1991; Levy \& Davis, 1988; Mikulincer \& Erev, 1991) and interpersonal processes (e.g., Bartholomew \& Horowitz, 1991; Mikulincer \& Nachshon, 1991; Simpson, Rholes, \& Nelligan, 1992), there has been relatively little work conducted examining the potential impact of attachment security on psychological distress and disorder in adulthood. This state of affairs is particularly surprising given both the well-documented association between insecure attachments in infancy and behavior problems (e.g., Sroufe, 1988) and theory linking internal working models (mental representations of the self and others) formed in infancy to adult psychological disturbance (Bowlby, 1980; Bretherton, 1987; Cummings \& Cicchetti, 1990; Diamond \& Blatt, 1994; Gotlib \& Hammen, 1992).

Nevertheless, the few studies that have examined the relation between adult attachment and psychological distress are encouraging. For example, insecure adult attachment has been found to be associated with affective distress, including depression (Armsden, McCauley, Greenberg, Burke, \& Mitchell, 1990; Kobak \& Sceery, 1988; Kobak, Sudler, \& Gamble, 1991); similarly, secure attachment appears to provide a buffer against the psychological distress typically associated with major life stressors (Hammen et al., 1995; Milkunicer et al., 1993). Depressed persons appear to be characterized by an anxious-ambivalent attachment style (Cole \& Kobak, 1990), as well as by a greater preoccupation with, and fearful avoidance of, attachment relationships (Carnelley et al., 1994). Finally, psychiatric outpatients with personality disorders and either dysthymia or an anxiety disorder have been found to be characterized by a feared loss of attachment figures (West, Rose, \& Sheldon, 1993). Despite this preliminary evidence that insecure adult attachment styles are related to various forms of psychological distress, the mechanism underlying this association remains unexplored.

Theory suggests that problematic attachment relationships become represented mentally as negative internal working models. Based on his or her history of transactions with important caregivers, the child begins to build models or representations concerning the self and others. These are essentially operating rules and expectations concerning the availability of support from caregivers, as well as the implications of the 
caregiver's responsiveness in terms of the self, including selfesteem, self-efficacy, acceptability, and lovability (Bretherton, 1987). Thus, working models partly involve the rules or conditions by which self-worth is achieved and maintained. As noted by others, working models of the self and others are often symmetrical. Thus, an unresponsive caregiver frequently leads not only to a working model of others as unreliable but also to a model of the self as unworthy of support and affection, or only worthy if particular conditions are met (cf. Rogers, 1961). Such expectations influence the nature of new relationships and help maintain (but, of course, do not fully determine) specific patterns of relating over the life span ${ }^{1}$ (Bowlby, 1980; Bretherton, 1985, 1987; West \& Sheldon-Keller, 1994).

In terms of emotional problems, individual differences in attachment security are hypothesized to be associated with distress and disorder at least partially through the mediating role of cognition (Batgos \& Leadbeater, 1994; Cummings \& Cicchetti, 1990). That is, inadequate attachment security is posited to lead to working models consisting of negative beliefs about oneself and important others. In turn, the activation of these cognitive structures contributes to various forms of psychological distress, such as depression and anxiety. As noted by others (Cummings \& Cicchetti, 1990; Gotlib \& Hammen, 1992), such working models likely form the foundation for dysfunctional beliefs of the kind Beck (Beck, 1976, Beck, Rush, Shaw, \& Emery, 1979) hypothesized predispose individuals to emotional distress. These dysfunctional beliefs have been framed as "if then" rules concerning self-worth (e.g., "I'm nothing if a person I care about doesn't love me;" Kuiper \& Olinger, 1986; Kuiper, Olinger, \& MacDonald, 1988; Swallow \& Kuiper, 1988). As long as these contingencies of self-worth are met, the individual will maintain positive self-esteem and remain nondepressed. However, failures at meeting these contingencies lead to plunges in self-esteem and the onset of depressive symptomatology (Olinger, Kuiper, \& Shaw, 1987). Although he was not specific, Beck suggested that problematic parent-child relationships lead to these relatively enduring, underlying attitudes and assumptions which, in turn, predispose to depression later in life (Beck et al., 1979). Attachment theory suggests a similar process by which insecure attachment relationships are mentally coded as negative working models, which increase vulnerability to the impact of interpersonal stressors (e.g., loss) in adulthood (cf. Bowlby, 1980).

Consistent with this overall line of thinking, Carnelley et al. (1994, Study 1) demonstrated that the relation between negative childhood experiences and adult nonclinical depression is mediated by negative working models of the self and others. Similarly, Whisman and McGarvey (in press) found that dysfunctional attitudes partly mediate the relation between attachment toward the primary caretaker and depressive symptoms. Furthermore, other studies have found that insecurity in adult attachment is related to lower self-esteem (Collins \& Read, 1990; Feeney \& Noller, 1990). Unfortunately, to date this research has been exclusively cross-sectional in design.

\section{Current Research}

In this article, we present data from three studies that investigated how adult attachment styles might be related to symp- toms of depression. In particular, we hypothesized that adult attachment insecurity is associated with higher levels of depressive symptoms. More specifically, we hypothesized that this relation is mediated by dysfunctional attitudes (maladaptive contingencies of worth) and depletions in selfesteem. Our mediation model suggests that attachment insecurity is associated with dysfunctional attitudes, which, in turn, lead to decreases in self-esteem. Theoretically, childhood experiences with primary caregivers that lead to attachment insecurity also contribute to the development of maladaptive rules and expectations concerning the maintenance of selfworth (dysfunctional attitudes). Such rules, expectations, and attitudes are the basis of what some have referred to as negative working models (e.g., Bowlby, 1980; Bretherton, 1985). According to our model ( see also Kuiper et al., 1988), these rigid contingencies of self-worth predispose to depletions in self-esteem, which, in turn, are directly related to increases in depressive symptoms. In Study 1 we examined the magnitude of association between insecure adult attachment and depressive symptoms; in Studies 2 and 3 we tested the full mediation model with prospective designs. These studies allowed us to statistically control initial levels of depressive symptoms. Because self-report measures of depressive symptoms likely tap nonspecific distress in addition to depression (e.g., Gotlib, 1984), we also statistically controlled neuroticism in Study 3.

\section{Study 1}

The data for Study 1 were collected during a large prescreening session of students enrolled in introductory psychology at Northwestern University. The primary purpose of this study was to examine the magnitude of the association between attachment insecurity and depressive symptomatology.

\section{Method}

\section{Participants and Procedure}

Participants were 152 undergraduates who took part in this study as part of a course requirement. Complete data were available on 144 participants ( 88 women). Participants were administered an extensive battery of questionnaires in a single large testing session.

\section{Measures}

Adult attachment style. Hazan and Shaver's (1987) attachment prototypes were used to assess adult attachment styles. However, rather than Hazan and Shaver's (1987) forced-choice approach, participants were asked to rate the degree to which secure, avoidant, and anxious/ ambivalent adult attachment styles described them on 10-point scales

\footnotetext{
${ }^{1}$ Attachment security also remains stable throughout the life span partly due to continuity in environmental circumstances. For example, inconsistent parenting first evident in infancy is likely to continue throughout childhood. Similarly, individuals who during childhood developed representations of others as being unavailable are likely to end up with adult partners who tend to confirm these beliefs (see Andrews, 1989 , for a related discussion). On the other hand, environmental discontinuities can lead to changes in attachment style (Egeland \& Farber, 1984).
} 
(Levy \& Davis, 1988). In contrast to the forced-choice approach, this method provides an opportunity to examine individual differences within attachment categories and allows for the possibility that some individuals might be best characterized by a blend of two or more styles (see Simpson et al., 1992). In the current sample, 54\% of the participants rated the secure attachment prototype as most descriptive, $23 \%$ gave highest ratings to the avoidant prototype, and $15 \%$ gave highest ratings to the anxious/ambivalent prototype. Identical high ratings on two dimensions were given by $8 \%$ of the participants.

Depressive symptomatology. The Inventory to Diagnose Depression (IDD; Zimmerman, Coryell, Corenthal, \& Wilson, 1986) was used to measure depressive symptomatology. Although this instrument was designed to classify individuals categorically in terms of diagnostic criteria for major depression, it also provides an index of severity of depressive symptomatology. Treated as a continuous measure, the IDD correlates highly with the Beck Depression Inventory (BDI; $r=.87$ ) and the Hamilton Rating Scale ( $r=.80$; Zimmerman et al., 1986). In contrast to other commonly used self-report instruments, such as the BDI, the IDD represents a relatively pure measure of depressive symptomatology as defined by the Diagnostic and Statistical Manual of Mental Disorders-Fourth Edition (DSM-IV; American Psychiatric Association, 1994).

\section{Results}

\section{Descriptive Statistics}

Means and standard deviations for variables in the three studies are shown in Table 1. Gender differences were absent on variables of interest in Study 1. Men and women did not differ in how self-descriptive they rated secure, avoidant, and anxious/ambivalent adult attachment prototypes, all $t s$ (142) $<1.65$, all $p \mathrm{~s}>$.1. Furthermore, men and women did not differ with respect to depression severity, $t(142)=1.13, p>.1$. Similar to other studies (e.g., Feeney et al., 1994; Levy \& Davis, 1988), and as can be seen in Table 2, ratings of secure and avoidant attachment were negatively correlated, $r=-.68, P<$ .001: Participants who described themselves as more secure also described themselves as less avoidant. However, there was

Table 1

Means and Standard Deviations of Variables Across the Three Studies

\begin{tabular}{|c|c|c|c|c|c|c|}
\hline \multirow[b]{2}{*}{ Measure } & \multicolumn{2}{|c|}{ Study 1} & \multicolumn{2}{|c|}{ Study 2} & \multicolumn{2}{|c|}{ Study 3} \\
\hline & $M$ & $S D$ & $M$ & $S D$ & $M$ & $S D$ \\
\hline Secure Prototype & 6.0 & 2.5 & & & & \\
\hline Avoidant Prototype & 4.0 & 2.5 & & & & \\
\hline Ambivalent Prototype & 4.2 & 2.5 & & & & \\
\hline Close Dimension & & & 21.3 & 4.7 & 22.8 & 5.2 \\
\hline Depend Dimension & & & 17.7 & 5.5 & 19.5 & 5.1 \\
\hline Anxiety Dimension & & & 15.9 & 5.1 & 13.9 & 5.2 \\
\hline DAS & & & 120.8 & 30.3 & 128.5 & 23.1 \\
\hline Self-Esteem & & & 39.2 & 6.4 & 55.3 & 10.1 \\
\hline Neuroticism & & & & & 12.0 & 4.4 \\
\hline IDD at Session 1 & 12.3 & 8.4 & 13.2 & 8.5 & 10.3 & 6.5 \\
\hline IDD at Session 2 & & & 10.3 & 8.4 & 9.7 & 6.8 \\
\hline
\end{tabular}

Note. $\quad$ DAS $=$ Dysfunctional Attitude Scale. IDD = Inventory to Diagnose Depression. Self-esteem was measured on a 5-point scale in Study 2 and on a 7-point scale in Study 3.
Table 2

Correlation Matrix of Variables in Study 1

\begin{tabular}{llcr}
\hline \multicolumn{1}{c}{ Measures } & \multicolumn{1}{c}{1} & 2 & 3 \\
\hline 1. Secure & & & \\
2. Ambivalent & -.11 & & \\
3. Avoidant & $-.68^{* * *}$ & -.04 & \\
4. IDD & $-.28^{* *}$ & $.20^{*}$ & $.25^{* *}$ \\
\hline
\end{tabular}

Note. Secure $=$ Secure Prototype. Ambivalent $=$ Ambivalent Prototype. Avoidant $=$ Avoidant Prototype. IDD $=$ Inventory to Diagnose Depression.

${ }^{*} p<.05 .{ }^{* *} p<.01{ }^{* * *} p<.001$.

no significant association between secure and anxious/ ambivalent attachment styles, $r=-.11$, or between anxious/ ambivalent and avoidant attachment styles, $r=-.04$, both $p \mathrm{~s}>.10$.

\section{Association Between Adult Attachment and Depressive Symptoms}

As anticipated, participants' ratings of adult attachment styles were associated significantly with their ratings of the severity of their depressive symptoms. Higher depression was correlated with lower similarity to the secure prototype $(r=-.28)$ and greater similarity to the anxious/ambivalent $(r=.20)$ and avoidant $(r=.25$ ) prototypes. Although these correlations were small, each was statistically significant. In order to determine the overall magnitude of association between the three attachment measures and depression, attachment measures were entered simultaneously into a regression equation with depressive symptoms as the criterion variable. This equation was significant, $R^{2}=.12, F=6.44, p<.001$, indicating that scores on the three adult attachment styles together accounted for about $12 \%$ of the variance in depressive symptomatology. Anxious/ ambivalent attachment was the only prototype that made a unique contribution, $t(140)=2.35, p<.05$. Overall, this study suggests that insecurity in adult attachment is associated with symptoms of depression but that attachment styles alone cannot fully explain depression.

\section{Studies 2 and 3}

Studies 2 and 3 were part of larger prospective investigations of psychosocial vulnerability to depression and largely included identical measures. Both studies were concerned with testing whether dysfunctional attitudes and low self-esteem mediate the relation between adult attachment and depression. As discussed earlier, we predicted that attachment insecurity would be associated with dysfunctional attitudes. These maladaptive contingencies of worth would contribute to depleted levels of self-esteem, which, in turn, would be directly related to changes in depressive symptoms.

\section{Method}

\section{Participants and Procedure}

Participants in Study 2 were an unselected sample of 225 college students at the University of Pittsburgh. Complete data were available for 
Table 3

Correlation Matrix of Variables in Studies 2 and 3

\begin{tabular}{lcccccrrr}
\hline \multicolumn{1}{c}{ Measures } & 1 & 2 & 3 & 4 & 5 & 6 & 7 \\
\hline 1. Anxiety & & -.08 & $-.40^{* * *}$ & $.46^{* * *}$ & $-.28^{* *}$ & $.25^{* *}$ & $.18^{*}$ \\
2. Close & -.11 & & $.59^{* * *}$ & $-.27^{* *}$ & $.25^{* *}$ & $-.32^{* *}$ & $-.22^{*}$ & $-.27^{* * *}$ \\
3. Depend & $-.33^{* * *}$ & $.44^{* * *}$ & & $-.25^{* *}$ & .18 & -.16 & -.05 & $-.25^{* *}$ \\
4. DAS & $.36^{* * *}$ & $-.24^{* * *}$ & $-.25^{* * *}$ & & $-.49^{* * *}$ & $.35^{* * *}$ & $.39^{* * *}$ & $.48^{* * *}$ \\
5. Self-Esteem & $-.36^{* * *}$ & $.30^{* * *}$ & $.26^{* * *}$ & $-.50^{* * *}$ & & $-.44^{* * *}$ & $-.52^{* * * *}$ & $-.46^{* * *}$ \\
6. IDD at Session 1 & $.38^{* * *}$ & $-.19^{* *}$ & $-.28^{* * *}$ & $.45^{* * *}$ & $-.51^{* * *}$ & $.67^{* * *}$ & $.33^{* * *}$ \\
7. IDD at Session 2 & $.22^{* *}$ & $-.22^{* *}$ & $-.22^{* *}$ & $.35^{* * *}$ & $-.49^{* * *}$ & $.57^{* * *}$ & $.37^{* * *}$ \\
8. Neuroticism & & & & & & & & \\
\hline
\end{tabular}

Note. Study 2 data are presented below the diagonal. Study 3 data are presented above the diagonal. Anxiety $=$ Anxiety Dimension. Close $=$ Close Dimension. Depend $=$ Depend Dimension. DAS $=$ Dysfunctional Attitude Scale. IDD $=$ Inventory to Diagnose Depression.

${ }^{*} p<.05 . \quad{ }^{* *} p<.01, \quad{ }^{* * *} p<.001$.

218 participants ( 137 women). Ages ranged from 17 to 49 years with a mean of $20.3(S D=5.1)$. Participants in Study 3 were 121 female college students at Northwestern University, with complete data available for 119 participants. Ages ranged from 17 to 27 years $(M=18.6, S D=$ 1.3). For the purposes of another study, participants in Study 3 were selected as nondepressed during a large prescreening session. In particular, participants who met IDD symptom criteria for major depression, regardless of duration criteria, were excluded from this sample. ${ }^{2}$ In both studies, participants completed a large battery of questionnaires in groups composed of no more than 20 individuals. Whereas Study 2 used an 8-week prospective interval, Study 3 used a 6-week interval. Participants received course credit in exchange for participation.

\section{Measures}

Depressive symptomatology. The IDD (Zimmerman et al., 1986) was used to measure severity of depressive symptoms.

Adult attachment styles. Collins and Read's (1990) 18-item dimensional inventory was used to measure adult attachment security. This measure was developed by deconstructing Hazan and Shaver's (1987) original descriptions of attachment prototypes into individual sentences that were each rated separately. Factor analysis suggested three primary dimensions: the extent to which an individual is comfortable with closeness (Close; e.g., I find it relatively easy to get close to others); feels that others are dependable (Depend; e.g., I know that others will be there when I need them); and is fearful about being unloved or abandoned (Anxiety; e.g., I often worry about being abandoned; Collins \& Read, 1990). Participants rated items on a 5-point scale of self-descriptiveness. In Study 2, coefficient alphas were .64 for Close, .81 for Depend, and .66 for Anxiety. In Study 3 the corresponding reliabilities were $.76, .80$, and .78 .

Dysfunctional attitudes. The Dysfunctional Attitude Scale (DAS; Weissman \& Beck, 1978) is a 40 -item measure of beliefs that are thought to predispose individuals to depression. Items such as "If I fail at my work, then I am a failure as a person" and "I do not need the approval of other people in order to be happy" are rated on a 7-point belief scale. Coefficient alpha was .91 in Study 2 and .87 in Study 3.

Self-esteem. The Rosenberg Self-Esteem Scale is a measure of global self-regard consisting of 10 items with good face validity, for example, "On the whole, I am satisfied with myself" (Rosenberg, 1965, 1979). This instrument was scored on a 5-point Likert scale in Study 2 and a 7-point Likert scale in Study 3. Coefficient alpha was .88 in Study 2 and .89 in Study 3.
Neuroticism. The Eysenck Personality Inventory (Eysenck \& Eysenck, 1964) was administered in Study 3 during a mass testing session to all introductory psychology students. Coefficient alpha was .79 for the entire participant pool.

\section{Results}

\section{Study 2}

Descriptive statistics. Gender differences were largely minimal or absent on variables of interest. There were nonsignificant trends for women to endorse greater depressive symptomatology in both the first session, 13.9 versus $11.9, t(216)=1.68, p$ $<.1$, and the second session, 11.2 versus $8.9, t(216)=1.90, p<$ .06. Although men and women did not differ on the attachment dimensions Depend or Anxiety, both $t s(216)<1, p s>.1$. Men reported feeling significantly more comfortable getting close to others than did women, 22.2 versus $20.7, t(216)=2.23, p<.05$. As can be seen in Table 3, Depend and Close were moderately correlated $(r=.44)$, whereas Depend and Anxiety showed a smaller negative association $(r=-.33)$. Persons who felt that attachment figures were dependable were more comfortable becoming close to others and were less fearful about abandonment and of not being loved. Across the three dimensions of attachment, participants who reported greater security tended to report fewer dysfunctional attitudes, greater self-esteem, and fewer depressive symptoms.

Testing the full model. The model described in the introduction suggests that attachment security at Session 1 contributes to dysfunctional attitudes measured at the same time period. These attitudes predict lower levels of self-esteem at Session 2, which contribute to depressive symptoms at Session 2.

Similar to the approach taken by Nolen-Hoeksema, Parker, and Larson (1994), three simultaneous multiple regression analyses were conducted to test this model (see also Cohen \& Cohen, 1983, pp. 353-378). In the first analysis, the criterion

\footnotetext{
${ }^{2}$ Because of this procedure, participants in Study 3 had a restricted range of variance on the major dependent variable, depression. Although this selection procedure was used due to the nature of another study, it results in a rather conservative test of our model.
} 


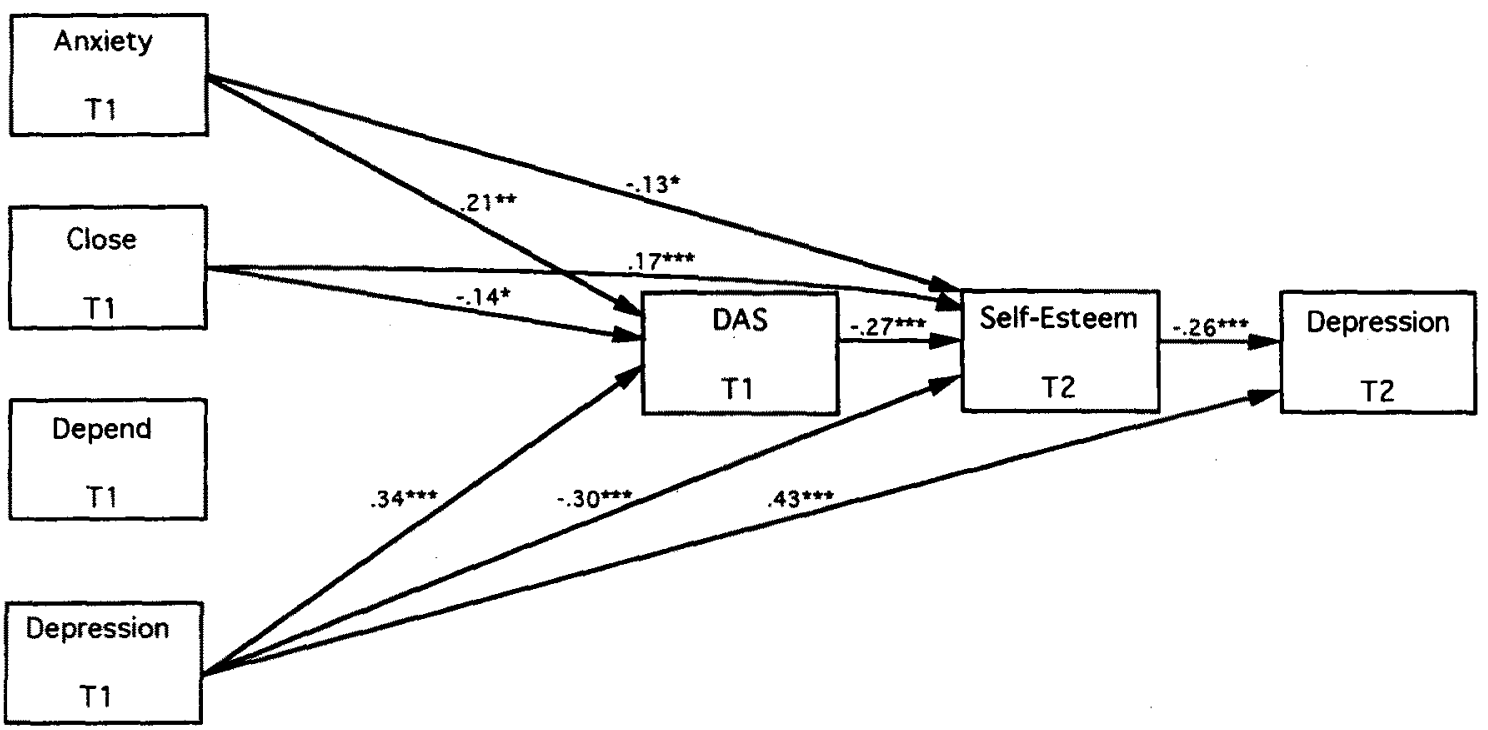

Figure 1. Path model in which dysfunctional attitudes and self-esteem mediate the relation between adult attachment security and depressive symptoms (Study 2 ). Anxiety = Anxiety Dimension; Close $=$ Close Dimension; Depend $=$ Depend Dimensions; $\mathrm{DAS}=$ Dysfunctional Attitude Scale; $\mathrm{T}=$ Time.

${ }^{*} p<.05 . \quad{ }^{* *} p<.01 . \quad{ }^{* * *} p<.001$.

variable was dysfunctional attitudes, and the predictor variables were the three dimensions of attachment and depressive symptoms measured at Session 1. This equation was significant, $R^{2}$ $=.27, F=19.31, p<.001$. Figure 1 displays the standardized beta weights of each variable after controlling for the effects of all other variables in each equation. As can be seen in the left half of the figure, participants who were anxious about attachment relations (Anxiety), as well as those who reported difficulties becoming close to attachment figures (Close), endorsed more dysfunctional attitudes, even after controlling for the effects of initial depressive symptoms.

In the second regression analysis, the criterion variable was self-esteem measured at Session 2, and the predictor variables were dysfunctional attitudes, the three dimensions of attachment, and initial depressive symptoms, all measured in Session 1. The squared multiple correlation was .39 ( $F=26.76, p<$ .001 ). As can be seen in Figure 1, participants who were more anxious about their attachment relations (Anxiety), who reported difficulties becoming close to attachment figures (Close), and who endorsed more dysfunctional attitudes experienced lower self-esteem 8 weeks later, even after controlling for initial depressive symptoms

In the third multiple regression analysis, the criterion variable was depressive symptoms measured at Session 2 and the predictor variables were depressive symptoms at Session 1, the three dimensions of attachment, dysfunctional attitudes, and self-esteem measured at Session 2 . This equation was significant $\left(R^{2}=.38, F=21.80, p<.001\right)$. As can be seen in Figure 1, attachment security and dysfunctional attitudes failed to make direct contributions to the prediction of depressive symptoms at Session 2. However, participants with lower self-esteem reported greater depressive symptoms at Session 2, even after con- trolling for the effects of initial depressive symptoms (as well as each of the other variables in the model).

\section{Study 3}

Descriptive statistics. Consistent with Study 2 , the dimension Depend was positively correlated with Close $(r=.58)$ and negatively correlated with Anxiety $(r=-.39)$. Individuals who felt that attachment figures were dependable were more comfortable becoming close to others and were less fearful about abandonment and not being loved. As can be seen in Table 3 , the dimensions Close and Anxiety were each significantly correlated with depressive symptoms and self-esteem. Individuals who were fearful about abandonment or of not being loved, and those who were uncomfortable being close to others, tended to be more depressed and had lower self-esteem. However, the degree to which participants found others dependable was not associated with depressive symptoms or self-esteem in this sample. Furthermore, across the three dimensions of attachment, insecurity was associated with the endorsement of dysfunctional attitudes.

Testing the full model. "As in Study 2, three simultaneous multiple regression analyses were conducted to test the hypothesized model. In addition to initial depressive symptoms, neuroticism was controlled in each analysis in this study. In the first analysis, the criterion variable was dysfunctional attitudes, and the predictor variables were the three dimensions of attachment, neuroticism, and depressive symptoms measured at Session 1. The squared multiple correlation was $.37(F=13.27, p$ $<.001$ ). As can be seen in Figure 2 and consistent with the results of Study 2, participants who were anxious about attachment relations (Anxiety), as well as those who reported diffi- 


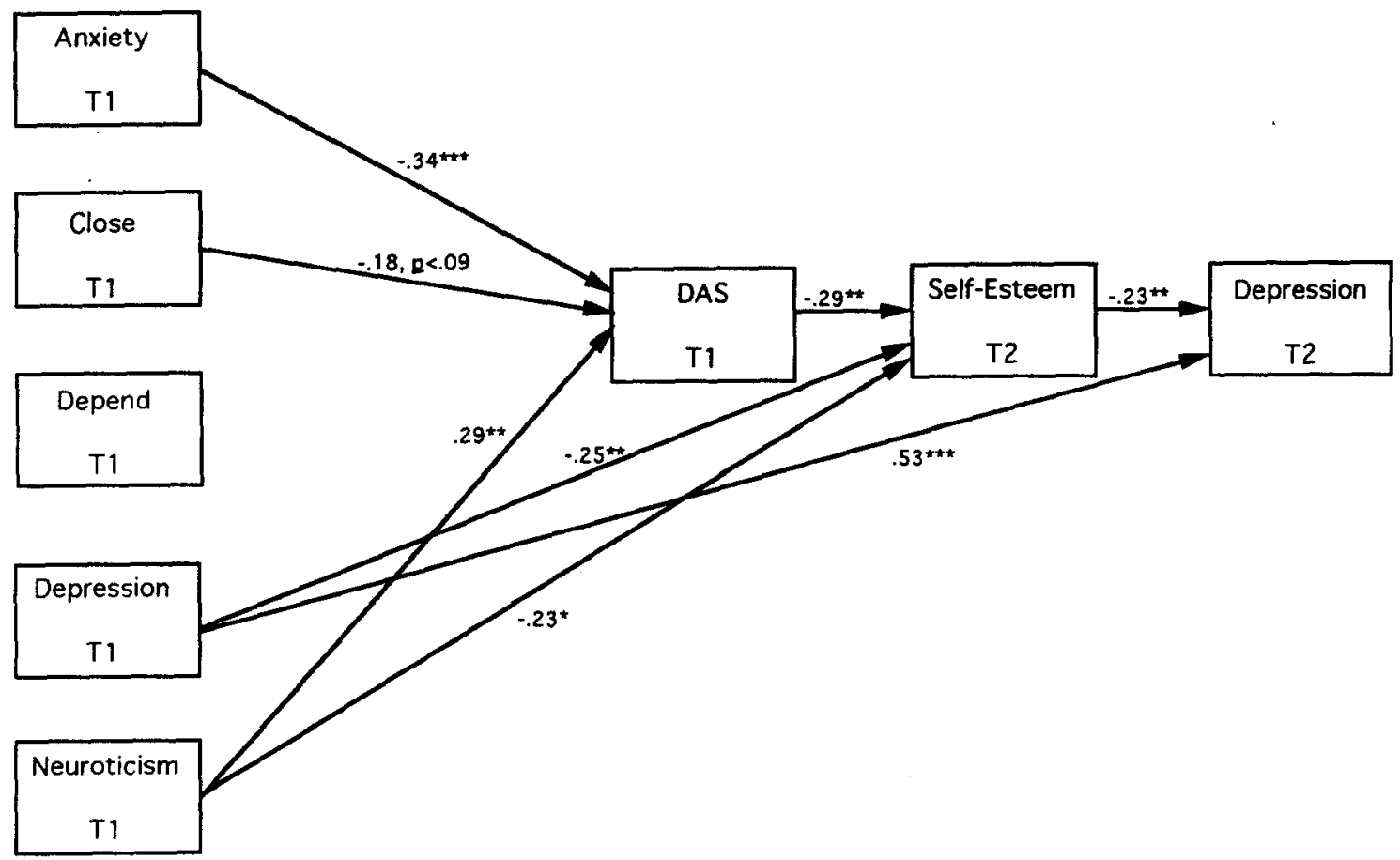

Figure 2. Path model in which dysfunctional attitudes and self-esteem mediate the relation between adult attachment security and depressive symptoms (Study 3 ). Anxiety $=$ Anxiety Dimension; Close $=$ Close Dimension; Depend $=$ Depend Dimension; DAS $=$ Dysfunctional Attitude Scale; $T=$ Time. ${ }^{*} p<.05$. ${ }^{* *} p<.01 . \quad{ }^{* * *} p<.001$.

culties becoming close to attachment figures (Close), endorsed more dysfunctional attitudes, even after controlling for the effects of neuroticism and initial depressive symptoms.

In the second regression analysis, the criterion variable was self-esteem measured at Session 2 , and the predictor variables were dysfunctional attitudes, the three dimensions of attachment, neuroticism, and initial depressive symptoms. The squared multiple correlation was $.37(F=10.82, p<.001)$. As can be seen in Figure 2, participants with more dysfunctional attitudes reported lower self-esteem 6 weeks later, even after controlling for neuroticism, initial depressive symptoms, and attachment security. Likewise, neuroticism and initial depressive symptoms made direct contributions to the prediction of self-esteem. Participants who were more neurotic and more symptomatically depressed reported lower self-esteem 6 weeks later. However, in contrast to Study 2, attachment security failed to make a significant unique contribution to the prediction of self-esteem.

In the third multiple regression analysis, the criterion variable was depressive symptoms measured at Session 2, and the predictor variables were neuroticism, depressive symptoms at Session 1, the three dimensions of attachment, dysfunctional attitudes, and self-esteem measured at Session 2 . This equation was significant $\left(R^{2}=.53, F=17.79, p<.001\right)$. As can be seen in Figure 2, participants with lower self-esteem reported greater depressive symptoms at Session 2, even after controlling neuroticism, initial depressive symptoms, attachment security, and dysfunctional attitudes. Initial depressive symptoms was the only other variable that made a direct contribution to the prediction of depressive symptoms at Session 2.

\section{General Discussion}

The present research was conducted to test the hypotheses that (a) insecure adult attachment is associated with depressive symptoms and (b) this relation is mediated by dysfunctional attitudes and depleted levels of self-esteem. Results obtained across three samples at two universities ( $\operatorname{total} n=486$ ) support both hypotheses.

Across the three samples, adult attachment styles were associated with dysfunctional attitudes, self-esteem, and depressive symptoms. Individuals who reported believing that others were less available when needed, feeling less comfortable becoming close to others, and worrying about abandonment and not being loved tended to endorse higher levels of dysfunctional attitudes, lower self-esteem, and elevated symptoms of depression. Most importantly, our data indicate that the relation between adult attachment and depression is mediated almost entirely by maladaptive contingencies of worth and low self-esteem. Adult attachment styles appear to exert little or no direct influence on depression and instead operate indirectly through negative thinking about the self. More specifically, our data are consistent with a model that suggests that insecurity in adult attachment is associated with dysfunctional attitudes, which in turn 
contribute to lower self-esteem. Depleted levels of self-esteem then act as a more proximal cause of depressive symptoms. Importantly, this model was supported when initial depressive symptoms and neuroticism were controlled statistically.

These findings contribute to an emerging understanding of the developmental and interpersonal antecedents of cognitive vulnerability to depression. Previous research has found that early adverse interpersonal experiences, such as inadequate parenting, contribute to negative cognitive styles (Blatt \& Homann, 1992; Brewin, Firth-Cozens, Furnham, \& McManus, 1992; Jaenicke et al., 1987; Whisman \& Kwon, 1992). Our results suggest that such vulnerabilities (dysfunctional attitudes and low self-esteem) also may be influenced by insecurity in adult attachment. Such insecurity presumably results from a lifetime of negative transactions with important attachment figures (West \& Sheldon-Keller, 1994). Although attachment insecurity is thought to develop in early childhood in response to inconsistent or unavailable parents (e.g., Bretherton, 1987; Main et al., 1985; Rothbard \& Shaver, 1994), continuity of attachment insecurity across the life span results both from the internalization of those early relationship experiences into internal working models, and from confirmation of those representations in contemporary relationships (West \& Sheldon-Keller, 1994). Thus, important interpersonal relationships might affect cognitive vulnerability to depression throughout the life span.

Furthermore, our data suggest that deficits in interpersonal functioning (at least attachment insecurity) contribute to depression through their impact on individuals' rules or procedures for attaining and maintaining a sense of self-worth and their success at achieving self-esteem. Persons who feel insecurely attached, perhaps due to current relationship difficulties, but who maintain a healthy sense of self-esteem and few dysfunctional contingencies of worth, appear less likely to become depressed. In contrast, individuals who have developed maladaptive contingencies of worth and who exhibit depleted selfesteem are likely to experience depressive symptoms regardless of their attachment security. Attachment insecurity, particularly worries about abandonment and about not being loved, as well as difficulties becoming close to others, seem to contribute to the development of depressive symptoms because they are associated with rigid and unrealistic rules concerning self-worth and consequent depleted levels of self-esteem. In contrast, concerns about the dependability of attachment figures do not appear to be associated with dysfunctional attitudes independent of the other two dimensions of attachment and our control variables (initial depressive symptoms and neuroticism).

Importantly, support for our mediation model was obtained when initial depressive symptoms were controlled statistically. As such, the model appears to be capable of predicting changes in depressive symptoms over prospective intervals as long as 8 weeks. Furthermore, Study 3 statistically controlled neuroticism, providing evidence that the model is associated with variance that is specific to depression, rather than simply general psychological distress. Although we included neuroticism largely to control general distress, other theoreticians and researchers have suggested that neuroticism is a dimension of per- sonality that itself increases risk for depression (e.g., Kendler, Kessler, Neale, Heath, \& Eaves, 1993; Martin, 1985; Roberts \& Gotlib, 1995). In fact, data from Study 3 were consistent with this formulation. However, our data suggest that neuroticism contributes to depressive symptoms largely indirectly through its effects on dysfunctional attitudes and self-esteem. Participants who were more neurotic endorsed greater numbers of dysfunctional attitudes and lower self-esteem (even after controlling concurrent depressive symptoms). In turn, dysfunctional attitudes and lower self-esteem lead to depressive symptoms, as we have outlined above. In contrast, neuroticism does not appear to directly contribute to depression.

Although self-report measures of adult attachment are widely used in the field, a number of questions remain concerning how well these instruments assess the attachment construct. First, questionnaire measures of adult attachment assume that individuals can accurately report these styles. In contrast, the standard interview approach for adult attachment (George, Kaplan, \& Main, 1985) does not assume that individuals necessarily can accurately report such matters. Similarly, attachment ratings of children are based on behavioral responses in a laboratory paradigm (the Strange Situation; Ainsworth et al., 1978). In fact, some have argued that the rules and underlying cognitive models concerning attachment are at least partly nonconscious (Bowlby, 1980; Brewin, 1989) and, therefore, quite difficult to measure through self-report. Furthermore, there is controversy concerning whether individuals can be classified into a single attachment style or whether people have multiple styles that vary across different relationships (e.g., Lewis, 1994). In this regard, it is likely that these multiple styles and representations form a hierarchy with one's attachment to the primary caregiver at the base (Hazan \& Shaver, 1994). Our data suggest that those aspects of one's central attachment style that are relatively accessible to consciousness are meaningfully related to depressive symptoms. Future research needs to examine how other aspects of attachment might contribute to risk for depression and other forms of psychological disorder.

Although our mediational model was verified in two nonclinical samples, it is an open question whether such findings would generalize to more severe forms of depression. In this regard, Carnelley et al. (1994) found somewhat different relations between working models and depression in student and patient samples. More specifically, nonclinical depression was associated with adult attachment styles involving negative working models of both the self and others, whereas clinical depression was associated with attachment styles involving negative working models of the self but positive models of others. Therefore, it is particularly important that the present findings be replicated in a clinical sample. Interestingly, our findings were consistent across both an unselected student sample and a sample selected based on low depression scores. The latter sample necessarily had reduced variance in the central dependent measure, depression. Consequently, this study provided a conservative test of our hypotheses and its positive findings testify to the potential strength of our model.

In addition to investigating this model in clinical samples, future research should examine whether it is specific to depres- 
sion or applies to other forms of disorder. Although results from Study 3 suggest that the mediational model can explain variance in depressive symptoms that is not shared with neuroticism (i.e., variance that is specific to depression), attachment insecurity might still play an important role in other conditions. For example, negative representations of the self, including dysfunctional contingencies of worth and low self-esteem, might mediate between attachment insecurity and anxiety. However, it is likely that the specific nature of attachment relationships and negative working models would differ in depressed and anxious individuals. In depressed persons, themes of loss and selfdeficiency might be prominent (Guidano, 1987), whereas elements of danger (i.e., fear of future loss) might predominate in anxious individuals (Ingram, Kendall, Smith, Donnell, \& Ronan, 1987). In this vein, one study linked specific variants of insecure adult attachment to specific psychological disorders (Cole \& Kobak, 1990), suggesting that particular patterns of insecure attachment might not generalize from one form of distress to another. Future research of this nature would be contingent on the development of more refined measures of attachment security and working models.

Finally, future research should examine the role of attachment security in buffering (or, conversely, exacerbating) the negative impact of stressful life events. In this regard, two recent studies (Hammen et al., 1995; Mikulincer et al., 1993) found that adult attachment styles moderated the impact of major life stressors, but the mechanism by which this process operated was not ascertained. Our model suggests that the activation of dysfunctional attitudes and depletions in self-esteem might mediate such relations. These and other related questions are best addressed by prospective studies assessing changes in symptomatology over time, as well as by longitudinal investigations of clinical relapse in remitted depressives.

\section{References}

Ainsworth, M. D. S., Blehar, M. C., Waters, E., \& Wall, S. (1978). Patterns of attachment: A psychological study of the strange situation. Hillsdale, NJ: Erlbaum.

American Psychiatric Association. (1994). The diagnostic and statistical manual of mental disorders (4th ed.). Washington, DC: Author.

Andrews, J. D. W. (1989). Psychotherapy of depression: A self-confirmation model. Psychological Review, 96, 576-607.

Armsden, G. C., McCauley, E., Greenberg, M. T., Burke, P. M., \& Mitchell, J. R. (1990). Parent and peer attachment in early adolescent depression. Journal of Abnormal Child Clinical Psychology, 18, 683-697.

Barnett, P. A., \& Gotlib, I. H. (1988). Psychosocial functioning and depression: Distinguishing among antecedents, concomitants, and consequences. Psychological Bulletin, 104, 97-126.

Bartholomew, K. (1994). Assessment of individual differences in adult attachment. Psychological Inquiry, 5, 23-27.

Bartholomew, K., \& Horowitz, L. M. (1991). Attachment styles among young adults: A test of a four-category model. Journal of Personality and Social Psychology, 61, 226-244.

Batgos, J., \& Leadbeater, B. J. (1994). Parental attachment, peer relations, and dysphoria in adolescence. In M. B. Sperling \& W. H. Berman (Eds.), Attachment in adults: Clinical and developmental perspectives. New York: Guilford Press.

Beach, S. R. H., Sandeen, E. E., \& O'Leary, K. D. (1990). Depression in marriage: A model for etiology and treatment. New York: Guilford Press.

Beck, A. T. (1976). Cognitive therapy and the emotional disorders. New York: International Universities Press.

Beck, A. T., Rush, A. J., Shaw, B. F., \& Emery, G. (1979). Cognitive therapy of depression. New York: Guilford Press.

Blatt, S. J., \& Homann, E. (1992). Parent-child interaction in the etiology of depression. Clinical Psychology Review, 12, 47-91.

Bowlby, J. (1969). Attachment and loss: Vol. 1. Attachment. New York: Basic Books.

Bowlby, J. (1973). Attachment and loss: Vol. 2. Separation: Anxiety and anger. New York: Basic Books.

Bowlby, J. (1980). Attachment and loss: Vol. 3. Loss, sadness, and depression. New York: Basic Books.

Bretherton, I. (1985). Attachment theory: Retrospect and prospect. In I. Bretherton \& E. Waters (Eds.), Growing points of attachment theory and research. Monographs of the Society for Research in Child Development, 50, 3-35.

Bretherton, I. (1987). New perspectives on attachment relations: Security, communication and internal working models. In J. D. Osofsky (Ed.), Handbook of infant development (2nd ed., pp. 1061-1100) New York: Wiley.

Brewin, C. R. (1989). Cognitive change processes in psychotherapy. Psychological Review, 98, 379-394.

Brewin, C. R., Firth-Cozens, J., Furnham, A., \& McManus, C. (1992). Self-criticism in adulthood and recalled child experience. Journal of Abnormal Psychology, 101, 561-566.

Brown, G. W., Bifulco, A., \& Andrews, B. (1990). Self-esteem and depression. 4. Effect on course and recovery. Social Psychiatry and Psychiatric Epidemiology, 25, 244-249.

Brown, G. W., Bifulco, A., Harris, T. O., \& Bridge, L. (1986). Social support, self-esteem and depression. Psychological Medicine, 16, 813-831.

Carnelley, K. B., \& Janoff-Bulman, R. (1992). Optimism about love relationships: General vs. specific lessons from one's personal experiences. Journal of Social and Personal Relationships, 9, 5-20.

Carnelley, K. B., Pietromonaco, P. R., \& Jaffe, K. (1994). Depression, working models of others, and relationship functioning. Journal of Personality and Social Psychology, 66, 127-140.

Cohen, J., \& Cohen, P. (1983). Applied multiple regression/correlation analysis for the behavioral sciences (2nd ed.). Hillsdale, NJ: Erlbaum.

Cole, H., \& Kobak, R. (1990, August). The role of parent-teen relationships in eating disorder and depression: An attachment perspective. Paper presented at the annual meeting of the American Psychological Association, Boston.

Collins, N. L., \& Read, S. J. ( 1990). Adult attachment, working models, and relationship quality in dating couples. Journal of Personality and Social Psychology, 58, 644-663.

Corney, R. H. (1987). Marital problems and treatment outcome in depressed women: A clinical trial of social work intervention. British Journal of Psychiatry, 151, 652-659.

Cummings, E. M., \& Cicchetti, D. (1990). Toward a transactional model of relations between attachment and depression. In M. T. Greenberg, D. Cicchetti, \& E. M. Cummings (Eds.), Attachment in the preschool years: Theory, research, and intervention (pp. 339372). Chicago: University of Chicago Press.

Dent, J., \& Teasdale, J. D. (1988). Negative cognition and the persistence of depression. Journal of Abnormal Psychology, 97, 29-34.

Diamond, D., \& Blatt, S. J. (1994). Internal working models and the representational world in attachment and psychoanalytic theories. In M. B. Sperling \& W. H. Berman (Eds.), Attachment in adults: Clini- 
cal and developmental perspectives (pp. 72-97). New York: The Guilford Press.

Egeland, B., \& Farber, E. A. ( 1984). Infant-mother atachment: Factors related to its development and changes over time. Child Development, 55, 753-771.

Eysenck, H. J., \& Eysenck, S. B. G. (1964). Eysenck Personality Inventory. San Diego, CA: Educational and Industrial Testing Service.

Feeney, J. A., \& Noller, P. (1990). Attachment style as a predictor of adult romantic relationships. Journal of Personality and Social Psychology, 58, 281-291.

Feeney, J. A., Noller, P., \& Hanrahan, M. (1994). Assessing adult attachment. In M. B. Sperling \& W. H. Berman (Eds.), Attachment in adults: Clinical and developmental perspectives (pp. 128-152). New York: Guilford Press.

George, C., Kaplan, N., \& Main, M. (1985). The adult attachment interview. Unpulished manuscript, University of California, Berkeley.

Gotlib, I. H. (1984). Depression and general psychopathology in university students. Journal of Abnormal Psychology, 93, 19-31.

Gotlib, I. H. ( 1992). Interpersonal and cognitive aspects of depression. Current Directions in Psychological Science, 1, 149-154.

Gotlib, I. H., \& Hammen, C. L. (1992). Psychological aspects of depression: Toward a cognitive interpersonal integration. Chichester, England: Wiley.

Gotlib, I. H., \& Robinson, L. A. (1982). Responses to depressed individuals: Discrepancies between self-report and observer-rated behavior. Journal of Abnormal Psychology, 91, 231-240.

Guidano, V. F. ( 1987). Complexity of the self. New York: The Guilford Press.

Haaga, D. A. F., Dyck, M. J., \& Ernst, D. ( 1991). Empirical status of cognitive theory of depression. Psychological Bulletin, 110, 215-236.

Hammen, C. L., Burge, D., Daley, S. E., Davila, J., Paley, B., \& Rudolph, K. D. (1995). Interpersonal attachment cognitions and prediction of symptomatic responses to interpersonal stress. Journal of Abnormal Psychology, 104, 436-443.

Hazan, C., \& Shaver, P. R. (1987). Romantic love conceptualized as an attachment process. Journal of Personality and Social Psychology, 52 , 511-524.

Hazan, C., \& Shaver, P. R. (1990). Love and work: An attachmenttheoretical perspective. Journal of Personality and Social Psychology, $59.270-280$.

Hazan, C., \& Shaver, P. R. (1994). Attachment as an organizational framework for research on close relationships. Psychological Inquiry, 5, 1-22.

Hooley, J. M., Orley, J., \& Teasdale, J. D. (1986). Levels of expressed emotion and relapse in depressed patients. British Journal of Psychiatry, 148, 642-647.

Hooley, J. M., \& Teasdale, J. D. (1989). Predictors of relapse in unipolar depressives: Expressed emotion, marital distress and perceived criticism. Journal of Abnormal Psychology, 98, 229-235.

Ingram, R. E., Kendall, P. C., Smith, T. W., Donnell, C., \& Ronan, K. (1987). Cognitive specificity in emotional distress. Journal of Personality and Social Psychology, 53, 734-742.

Jaenicke, C., Hammen, C., Zupan, B., Hiroto, D., Gordon, D., Adrian, C., \& Burge, D. (1987). Cognitive vulnerability in children at risk for depression. Journal of Abnormal Child Psychology, 15, 559-572.

Joiner, T. E., \& Metalsky, G. I. (1993). Caught in the crossfire: Depression, self-consistency, self-enhancement, and the response of others. Journal of Social and Clinical Psychology, 12, 114-135.

Keitner, G. I., Miller, I. W., Epstein, N. B., Bishop, D. S., \& Fruzzetti, A. E. (1987). Family functioning and the course of major depression. Comprehensive Psychiatry, 28, 54-64.

Kendler, K. S., Kessler, R. C., Neale, M. C., Heath, A. C., \& Eaves, L. J. (1993). The prediction of major depression in women: Toward an integrated etiologic model. American Journal of Psychiatry, 150 1139-1148.

Kobak, R. (1994). Adult attachment: A personality or relationship contruct? Psychological Inquiry, 5, 42-44.

Kobak, R. R., \& Hazan C. (1991). Attachment in marriage: Effects of security and accuracy of working models. Joumal of Personality and Social Psychology, 60, 861-869.

Kobak, R. R., \& Sceery, A. (1988). Attachment in late adolescence: Working models, affect regulation, and representations of self and others. Child Development, 59, 135-146.

Kobak, R. R., Sudler, N., \& Gamble, W. (1991). Attachment and depressive symptoms during adolescence: A developmental pathways analysis. Development and Psychopathology, 3, 461-474.

Kuiper, N. A., \& Olinger, L. J. (1986). Dysfunctional attitudes and a self-worth contingency model of depression. Advances in CognitiveBehavioral Research and Therapy, 5, 115-142.

Kuiper, N. A., Olinger, L. J., \& MacDonald, M. R. (1988). Vulnerability and episodic cognitions in a self-worth contingency model of depression. In L. B. Alloy (Ed.), Cognitive processes in depression (pp. 289-309). New York: Guilford Press.

Levy, M. B., \& Davis, K. E. (1988). Love styles and attachment styles compared: Their relations to each other and to various relationship characteristics. Journal of Social and Personal Relationships, 5, 439471.

Lewinsohn, P. M., Hoberman, H., Teri, L., \& Hautzinger, M. (1985). An integrative theory of depression. In S. Reiss \& R. Bootzin (Eds), Theoretical issues in behavior therapy (pp. 331-359). New York: Academic Press.

Lewinsohn, P. M., Steinmetz, J. L., Larson, D. W., \& Franklin, J. (1981). Depression-related cognitions: Antecedent or consequence? Journal of Abnormal Psychology, 90, 213-219.

Lewis, M. (1994) Does attachment imply a relationship or multiple relationships? Psychological lnquiry, 5, 47-51.

Main, M., Kaplan, N., \& Cassidy, J. (1985). Security in infancy, childhood, and adulthood: A move to the level of representation. Monographs of the Society for Research in Child Development, 50, 66-104.

Main, M., \& Weston, D. R. (1981). The quality of the toddler's relationship to mother and to father: Related to conflict behavior and the readiness to establish new relationships. Child Development, 52, 932940.

Martin, M. (1985). Neuroticism as predisposition toward depression: A cognitive mechanism. Personality and Individual Differences, 6 , 353-365.

Mikulincer, M., \& Erev, I. (1991). Attachment style and the structure of romantic love. British Journal of Social Psychology, 30, 273-291.

Mikulincer, M., Florian, V., \& Tolmatz, R. (1990). Attachment styles and fear of personal death: A case study of affect regulation. Journal of Personality and Social Psychology, 58, 273-280.

Mikulincer, M., Florian, V., \& Weller, A. (1993). Attachment styles, coping strategies, and posttraumatic psychological distress: The impact of the Gulf War in Israel. Journal of Personality and Social Psychology, 64, 817-826.

Mikulincer, M., \& Nachshon, O. (1991). Attachment styles and patterns of self-disclosure. Journal of Personality and Social Psychology, $61,273-280$.

Nolen-Hoeksema, S., Parker, L. E., \& Larson, J. ( 1994). Ruminative coping with depressed mood following loss. Journal of Personality and Social Psychology, 67, 92-104.

Olinger, L. J., Kuiper, N. A., \& Shaw, B. F. (1987). Dysfunctional attitudes and stressful life events: An interactive model of depression. Cognitive Therapy and Research, 11, 25-40.

Roberts, J. E., \& Gotlib, I. H. (1995). Vulnerability to episodes of de- 
pression: Gender, early childhood loss, and neuroticism. Manuscript submitted for publication.

Roberts, J. E., \& Monroe, S. M. (1994). A multidimensional model of self-esteem in depression. Clinical Psychology Review, 14, 161-181.

Rogers, C. R. (1961). On becoming a person. Boston: Houghton Mifflin.

Rosenberg, M. (1965). Society and the adolescent self-image. Princeton, NJ: Princeton University Press.

Rosenberg, M. (1979). Conceiving the self. New York: Basic Books.

Rothbard, J. C., \& Shaver, P. R. (1994). Continuity of attachment across the life-span. In M. B. Sperling \& W. H. Berman (Eds.), Attachment in adults: Clinical and developmental perspectives (pp. 3171). New York: Guilford Press.

Rounsaville, B. J., Weissman, M. M., Prusoff, B. A., \& Herceg-Baron, R. L. (1979). Marital disputes and treatment outcome in depressed women. Comprehensive Psychiatry, 20, 483-490.

Safran, J. D., \& Segal, Z. V. (1990). Interpersonal process in cognitive therapy. New York: Basic Books.

Segal, Z. V., \& Muran, J. C. (1993) A cognitive perspective on selfrepresentation in depression. In Z. V. Segal \& S. J. Blatt (Eds.), The self in emotional distress. New York: Guilford Press.

Simons, A. D., Murphy, G. E., Levine, J. L., \& Wetzel, R. D. (1986). Cognitive therapy and pharmacotherapy for depression: Sustained improvement over one year. Archives of General Psychiatry, 43, 4348.

Simpson, J. A., Rholes, W. S., \& Nelligan, J. S. ( 1992). Support-seeking and support-giving within couple members in an anxiety-provoking situation: The role of attachment styles. Journal of Personality and Social Psychology, 62, 434-446.

Sroufe, L. A. (1988). The role of infant-caregiver attachment in development. In J. Belsky \& T. Nezworski (Eds.), Clinical implications of attachment (pp. 18-38). Hillsdale, NJ: Erlbaum.

Sroufe, L. A., \& Waters, E. (1977). Attachment as an organizational construct. Child Development, 61, 1363-1373.

Steinmetz, J. L., Lewinsohn, P. M., \& Antonuccio, D. O. (1983). Prediction of individual outcome in a group intervention for depression. Journal of Consulting and Clinical Psychology, 51, 331-337.

Swallow, S. R., \& Kuiper, N. A. ( 1988). Social comparisons and nega- tive self-evaluations: An application to depression. Clinical Psychology Review, 8, 55-76.

Swindle, R. W., Jr., Cronkite, R. C., \& Moos, R. H. (1989). Life stressors, social resources, coping, and the 4-year course of unipolar depression. Journal of Abnormal Psychology, 98, 468-477.

Teasdale, J. D., \& Barnard, P. J. (1993). Affect, cognition, and change: Re-modelling depressive thought. Hillsdale, $\mathrm{NJ}$ : Erlbaum.

Vaughn, C. E., \& Leff, J. P. (1976). The influence of family and social factors on the course of psychiatric illness. British Journal of Psychiatry, 129, 125-137.

Waters, E. (1978). The reliability and stability of individual differences in infant-mother attachment. Child Development, 49, 483-494.

Weissman, A. N., \& Beck, A. T. (1978). Development and validation of the Dysfunctional Attitude Scale: A preliminary investigation. Paper presented at the annual meeting of the American Educational Research Association, Toronto, Ontario, Canada.

West, M. L., Rose, M. S., \& Sheldon, A. (1993). Anxious attachment as a determinant of adult psychopathology. Journal of Nervous and Mental Disorders, 181, 422-427.

West, M. L., \& Sheldon-Keller, A. E. (1994). Patterns of relating: An adult attachment perspective. New York: Guilford Press.

Whisman, M. A., \& Kwon, P. (1992). Parental representations, cognitive distortions, and mild depression. Cognitive Therapy and Research, 16, 557-568.

Whisman, M. A., \& McGarvey, A. L. (in press). Attachment, depressotypic cognitions, and dysphoria. Cognitive Therapy and Research.

Williams, J. M. G., Healy, D., Teasdale, J. D., White, W., \& Paykel, E. S. (1990). Dysfunctional attitudes and vulnerability to persistent depression. Psychological Medicine, 20, 375-381.

Williams, J. M. G., Watts, F. N., MacLeod, C., \& Mathews, A. (1988). Cognitive psychology and emotional disorders. New York: Wiley.

Zimmerman, M., Coryell, W., Corenthal, C., \& Wilson, S. (1986). A self-report scale to diagnose major depressive disorder. Archives of General Psychiatry, 43, 1076-1081.

Received July 28,1994

Revision received February 13, 1995

Accepted May 16, 1995 